\title{
Demographic and clinical profile with early outcome of critically ill COVID-19 patients admitted in an ICU of a tertiary care hospital in Dhaka, Bangladesh Ahsan ASMA ${ }^{a *}$, Sultana $\mathbf{R}^{\mathrm{b} *}$, Fatema $K^{\mathrm{c}}$, Ahmed $\mathrm{F}^{\mathrm{c}}$, Saha DK ${ }^{\mathrm{d}}$, Saha $\mathbf{M}^{\mathrm{b}}$, Nazneen $\mathbf{S}^{b}$, Jahan $\mathbf{I}^{\mathbf{e}}$
}

\begin{abstract}
Background: First outbreak of corona virus disease (COVID-19) started in Wuhan, China at December 2019 and since then, it spread globally but information about critically ill patients with COVID-19 is still limited. So, it is important to know the demographic profile and overall outcome of COVID-19 patients. We aimed to describe the clinic-demographic characteristics and outcome of critically ill COVID-19 patients admitted in our intensive care unit.

Methods: This prospective observational study was carried out in the intensive care unit of department of Critical Care Medicine of BIRDEM General Hospital, Dhaka, Bangladesh from $11^{\text {th }}$ June to $31^{\text {st }}$ October, 2020. Out of 382 suspected cases, 86 patients were found to be RT-PCR for COVID-19 positive and were included in this study. After admission in ICU, all patients were resuscitated according to ICU protocol. Length of ICU stay were recorded and patient outcomes were mentioned as survival (transferred or discharged) or death.

Results: A total of 86 patients (male 53, female 33, mean age 63.6 \pm 12.8 years) with RT-PCR for COVID-19 positive were enrolled in this study. Regarding COVID related symptoms, Ninety six percent(83) had respiratory distress, $93.02 \%(n=80)$ had cough, $84.9 \%(n=73)$ had history of fever, $11.6 \%(n=10)$ had loose motion and $7 \%(n=6)$, had anosmia. Diabetes mellitus (DM) was the most common co morbidity (91.9\%). For improvement of oxygenation of COVID patient, we treated $7 \%$ of patients $(n=6)$ by nasal Cannula, $24.4 \%(n=21)$ by Face Mask, 20.9\% $(n=18)$ by Non Rebreather Mask, 22.1\% $(n=19)$ by High Flow Nasal Cannula (HFNC) and $25.6 \%(n=22)$ by Mechanical Ventilation. Mean length of ICU stay were $6.9 \pm 3.6$ days and range of icu stay were 1-20 days. Among 86 COVID patient, $51.16 \%(n=44)$ were transferred to the isolation ward or discharged at home and $48.8 \%(n=42)$ were died.

Conclusion: This study showed the overall demographic and clinical features of critically ill COVID-19 patients, admitted in an icu of a tertiary care hospital. As it is a single centered study, we need more study with multi center approach to know the detail demographic profile and outcome of COVID-19 patients.
\end{abstract}

Key words: COVID-19, critically ill, RT-PCR, demographic profile, outcome.

(BIRDEM Med J 2020; 10, COVID Supplement: 51-55)

\footnotetext{
Author information

a. ASM Areef Ahsan, Professor and Head, Department of Critical Care Medicine, BIRDEM General Hospital, Dhaka, Bangladesh.

b. Rozina Sultana, Madhurima Saha, Suraiya Nazneen, Registrar, Department of Critical Care Medicine, BIRDEM General Hospital, Dhaka, Bangladesh.

c. Kaniz Fatema, Fatema Ahmed, Associate Professor, Department of Critical Care Medicine, BIRDEM General Hospital, Dhaka, Bangladesh.

d. Debasish Kumar Saha, Assistant Professor, Department of Critical Care Medicine, BIRDEM General Hospital, Dhaka, Bangladesh.

e. Israt Jahan, Senior Medical Officer, Department of Critical Care Medicine, BIRDEM General Hospital, Dhaka, Bangladesh.

*First two authors will be considered as first authors.

Address of correspondence: A.S.M. Areef Ahsan, Professor and Head, Department of Critical Care Medicine, BIRDEM General Hospital, Dhaka, Bangladesh. Email: dr_asmareef@yahoo.com

Received: December 1, 2020

Revision received: December 10, 2020

Accepted: December 15, 2020
} 


\section{INTRODUCTION}

COVID-19 pandemic caused by the novel coronavirus (SARS-CoV-2), is an emerging rapidly evolving situation. At the end of 2019, a novel coronavirus was identified as the cause of a cluster of pneumonia cases in Wuhan, a city in the Hubei Province of China. The disease is designated as COVID-19, which stands for coronavirus disease $2019 .{ }^{1}$ The virus that causes COVID-19 is mentioned severe acute respiratory syndrome coronavirus 2 (SARS-CoV-2); previously, it was referred to as 2019-nCoV.As, this virus spread rapidly across the globe, and the WHO subsequently declared COVID-19 (Coronavirus disease 2019) as a pandemic on March 11, 2020. ${ }^{2}$

The virus was confirmed to have spread to Bangladesh in March 2020. The first three known cases were reported on $8^{\text {th }}$ March 2020 , that was confirmed by the Institute of Epidemiology, Disease Control and Research (IEDCR) at a press conference.Since then, the pandemic has spread day by day over the whole nation and the number of affected people has been increasing. ${ }^{3}$

Bangladesh is the second most affected country in South Asia after India. ${ }^{4}$

During the period of national crisis, department of critical care medicine started to admit suspected COVID-19 cases in ICU from $11^{\text {th }}$ June, 2020. From $11^{\text {th }}$ June to $31^{\text {st }}$ October, 2020, a total of 382 suspected COVID 19 cases, were admitted, who were critically ill. Among them total 86 patients were found to be RT-PCR positive. In this study, the demographic profile and outcome of critically ill COVID-19 patients were evaluated.

The clinical presentation and outcome of patients with COVID-19 have been variable in different countries. ${ }^{5-8}$ Therefore, it is important to analyze and document the demographic profile and their outcome in our population. In this study we observed 86 COVID-19 patients, admitted to our ICU from this given time period.

\section{METHODS}

This prospective observational study was carried out in the Department of Critical Care Medicine (ICU) of BIRDEM General Hospital, Dhaka, Bangladesh from $11^{\text {th }}$ June to $31^{\text {st }}$ October, 2020. During this period, a total of 382 critically ill patients were admitted as a suspected case of COVID-19 on the basis of clinical symptoms (fever, cough, respiratory distress, anosmia and loose motion etc). Among them 86 patients were found to be RT-PCR positive. These RT-PCR positive COVID-19 patients were included in this study.Sample were collected from nasopharyngeal swab or blind tracheal aspirate(who were on mechanical ventilation). Data collection included demographics, symptoms on presentation, initial laboratory test, treatment course, length of ICU stay and outcome. The outcome was defined as survival (transferred or discharged) and death at ICU. The co-morbidities included DM, HTN, Asthma, COPD, IHD, CKD, ESRD and CLD.

After admission to ICU, all patients were resuscitated according to ICU protocol. Here patients were treated by Injection Remdesivir, Dexamethasone, Tociluzumab, Low molecular weight heparin and by convalescent plasma. To improve oxygenation we used Nasal Cannula, Face Mask, Non Rebreather Mask, HFNC (High Flow Nasal Cannula) and Mechanical Ventilation. Treatment of pre existing diseases were continued. Patients were discharged or transferred to the isolation ward or home after symptomatic, clinical and radiological improvement. Data were recorded in pretested structured data sheet and analyzed by using Statistical Package for Social Sciences (SPSS) software (version 18).

\section{RESULTS}

During this study period, total $382(\mathrm{~N}=382)$ suspected COVID-19 patients were admitted, among them $86(\mathrm{n}=86)$ were found to be RT-PCR positive $(22.5 \%$, $\mathrm{n}=86$, were positive and $77.5 \%, \mathrm{n}=296$, were negative). This $22.5 \%(\mathrm{n}=86)$ patients were included in this study. Among 86 patients, $61.6 \%(\mathrm{n}=53)$ were male and $38.4 \%(n=33)$ were female (Table I), mean age was $63.6 \pm 12.8$. (Table II).

Percentage of COVID-19 positive patient $(\mathrm{n}=86)$ among the suspected cases $(\mathrm{N}=382)$ :

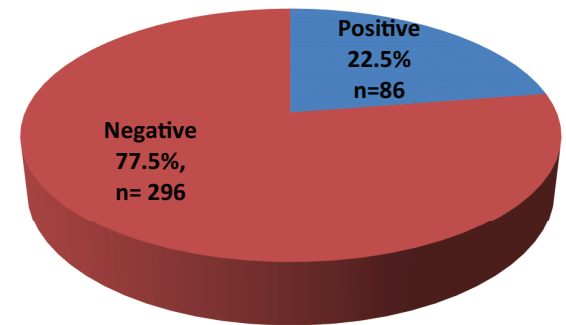

Figure 1 Frequency of COVID-19 positive cases 
Table I Distribution of COVID-19 positive cases according to sex ( $\mathrm{N}=86)$

\begin{tabular}{lcc}
\hline Sex & Frequency & Percentage \\
\hline Male & 53 & 61.6 \\
Female & 33 & 38.4 \\
\hline
\end{tabular}

Table II Distribution of COVID-19 positive cases according to age $(\mathrm{N}=86)$

\begin{tabular}{lcc}
\hline Age (years) & Frequency & Percentage \\
\hline$<50$ & 9 & 10.5 \\
$51-60$ & 24 & 27.9 \\
$61-70$ & 32 & 37.2 \\
$71-80$ & 17 & 19.8 \\
$>80$ & 4 & 4.7 \\
Mean \pm SD & \multicolumn{2}{c}{$63.6 \pm 12.8$} \\
Min - max & \multicolumn{3}{c}{$18-94$} \\
\hline
\end{tabular}

Regarding clinical symptoms, $96.5 \%(n=83)$ had respiratory distress, $93.02 \%(\mathrm{n}=80)$ had cough, $84.9 \%$ $(\mathrm{n}=73)$ had history of fever,11.6 \% $(\mathrm{n}=10)$ had loose motionand $7 \%(\mathrm{n}=6)$, had anosmia. (Table III). Among 86 patients, $95.3 \% \quad(n=82)$ got injection Dexamethasone, $79.1 \%(\mathrm{n}=68)$ injection Remdesivir, $11.6 \%(\mathrm{n}=10)$ Convalescent plasma, 4.7\% $(\mathrm{n}=4)$ injection Tociluzumab and $90.75 \%(n=78)$ got Low molecular weight heparin. (Table IV). Injection heparin couldn't given in $100 \%$ cases, as there were some contraindications in few patients like altered coagulation profile ,bleeding and thrombocytopenia.

\begin{tabular}{lcc}
\multicolumn{3}{l}{ Table III COVID-19 related symptoms } \\
\hline Symptoms & Frequency & Percentage \\
\hline Respiratory distress & 83 & 96.5 \\
Cough & 80 & 93.02 \\
Fever & 73 & 84.9 \\
Loose motion & 10 & 11.6 \\
Anosmia & 6 & 7.0 \\
\hline
\end{tabular}

*Multiple responses
Table IV Treatment given at ICU

\begin{tabular}{lcc}
\hline Treatment & Frequency & Percentage \\
\hline Inj. Dexamethasone & 82 & 95.3 \\
Inj. Remdesivir & 68 & 79.1 \\
Convalescent plasma & 10 & 11.6 \\
Inj. Tocilizumab & 4 & 4.7 \\
Low molecular heparin & 78 & 90.7 \\
\hline
\end{tabular}

*Multiple responses

For improvement of oxygenation of COVID patient, we treated $7 \%$ of patients $(n=6)$ by nasal Cannula, $24.4 \%$ $(\mathrm{n}=21)$ by Face Mask, $20.9 \%(\mathrm{n}=18)$ by Non Rebreather Mask, 22.1\% $(\mathrm{n}=19)$ by High Flow Nasal Cannula (HFNC) and $25.6 \%(\mathrm{n}=22)$ by Mechanical Ventilation. (Table V). Different types of co-morbidities were shown in a tabulated form (Table VI).

Table V Mode of oxygen delivery among COVID19 positive cases $(\mathrm{N}=86)$

\begin{tabular}{lcc}
\hline Mode & Frequency & Percentage \\
\hline Nasal Cannula (1 to 4) L/min & 6 & 7.0 \\
Face mask (5 to 10) L/min & 21 & 24.4 \\
Non rebreather mask (10 to 15) & 18 & 20.9 \\
L/min & & \\
High flow nasal Cannula & 19 & 22.1 \\
Mechanical ventilator & 22 & 25.6 \\
\hline
\end{tabular}

\section{Table VI Co morbidities}

\begin{tabular}{lcc}
\hline Co morbidity & Frequency & Percentage \\
\hline DM & 79 & 91.9 \\
HTN & 67 & 77.9 \\
Asthma & 12 & 14.0 \\
COPD & 15 & 17.4 \\
IHD & 17 & 19.8 \\
CKD & 16 & 18.6 \\
ESRD & 14 & 16.3 \\
CLD & 8 & 9.3 \\
Obesity & 15 & 17.4 \\
\hline
\end{tabular}

*Multiple responses 
Duration of ICU stay is variable in terms of severity of the disease. Mean length of ICU stay were $6.9 \pm 3.6$ days (Table VII). The outcome was defined as survival (transferred or discharged) and death at ICU. Among 86 COVID patient, $51.16 \%(\mathrm{n}=44)$ were transferred to the isolation ward or discharged at home, who were considered as survival and $48.8 \%(n=42)$ died.

\begin{tabular}{l}
\multicolumn{3}{l}{$\begin{array}{l}\text { Table VII Distribution of COVID-19 positive cases } \\
\text { according to length of ICU stay (N=86) }\end{array}$} \\
\begin{tabular}{lcc}
\hline Length of ICU stay (days) & Frequency & Percentage \\
\hline $1-5$ & 29 & 33.7 \\
$6-10$ & 46 & 53.5 \\
$11-15$ & 7 & 8.1 \\
$16-20$ & 4 & 4.7 \\
\hline
\end{tabular}
\end{tabular}

\section{DISCUSSION}

In this study a total 86 RT-PCR positive critically ill patients were included. Among them $61.6 \%(n=53)$ were male and $38.4 \%(n=33)$ were female. In our study there was significant difference in the proportion of male and female patients, which was consistent with the results of a study performed by Gaung et al in China.Their results showed that males were more likely to be infected than females $(58.1 \%$ male and $41.9 \%$ female). ${ }^{9}$

In our study, age distribution shows $<50$ years $(10.5 \%)$, in $51-60$ years $(27.9 \%)$, in $61-70$ years( $37.2 \%)$, in $71-$ 80 years $(19.8 \%)$ and $>80$ years $(4.7 \%)$. The age group were mostly affected in this study, were $61-70$ years $(\mathrm{n}=32,37.2 \%)$ and Mean age \pm SD was $63.6 \pm 12.8$. Shah $\mathrm{P}$ et.al shows the median age was 63 years and interquartile range, (50-72 years). ${ }^{10}$

Regarding clinical symptoms, in our study $96.5 \%$ patient presented with respiratory distress, $93.02 \%$ with cough, $84.9 \%$ with fever, $11.6 \%$ with loose motion and $7 \%$ patient presented with anosmia. In a study in Bangladesh by Ahmed NU et.al showed fever was the dominant symptoms ( $\mathrm{n}=154,77 \%) .{ }^{11}$ Fever also a dominant symptom seen by Guan et al, ${ }^{9}$ Wang et al ${ }^{12}$,Zangh et al. ${ }^{13}$ Ahmed N U et.al also showed $35.5 \%$ patient presented with cough. ${ }^{11} \mathrm{In}$ another study Xie $\mathrm{J}$ et al showed the most common presenting symptoms were fever $[630(85.9 \%)]$, dry cough $[550(75 \%)]$, and dyspnoea $[444(60.7 \%)] .{ }^{14} \mathrm{~A}$ systematic review by
Rodriguez-Morales et al 25 ofdata on 656 cases published in January and February2020 reported fever in $88.7 \%$, cough in $57.6 \%$, dyspnoeain $45.6 \%$, diarrhoea in $6.1 \% .^{15}$

In our study $91.9 \%$ had DM, 77.9\% had HTN, 14.0\% had Asthma, 17.4\% had COPD, 19.8\% had IHD, 18.6\% had CKD, 16.3\% ESRD and 9.3\% had CLD. Shah P et.al showed in their study, the most common co morbidities were HTN $(n=416,79.7 \%)$, obesity $(\mathrm{n}=347,66.5 \%)$ and DM $(\mathrm{n}=221,42.3 \%)$. Morbid obesity were present in $25.6 \%$ of patients. ${ }^{10}$ In another study byXie $\mathrm{J}$ et al showed among 733 critically ill patients, 454 had one or more co morbidities, with hypertension (42\%) as the most common co morbidity, followed by diabetes (18.8\%) and coronary heart disease $(12.7 \%)^{14}$

Here, we found that maximum length of stay (LOS) in ICU were $6-10$ days (53.5\%) and Mean \pm SD length of stay was $6.9 \pm 3.6$. In a study, Shah P et.al shows Median LOS was 6 days (IQR, 4-11 days. ${ }^{10}$

In this study, $51.16 \%(\mathrm{n}=44)$ patients were transferred to the isolation ward or discharged at home who were considered as survival and $48.8 \%(n=42)$ patients were died, among 86 cases. Xie J et al showed 53.8\% mortality in 733 critically ill patients with COVID 19 in their study. ${ }^{14}$

\section{Limitations}

Our study has certain limitations like any other study. First, it is a single centered study, for more information, multi centered analysis should be done. Second, our study period is short, we need long term follow up to get the actual mortality rate. Because true mortality of this disease cannot be estimated as some patient may die later from complications of this disease or prolong hospitalization itself. Third, we did not include the cause of death in critically ill COVID 19 patients in our study. Fourth, this study was conducted in a tertiary care hospital where most of the patient populations were diabetic and having pre-existing multiple co morbidities.

\section{Conclusion}

This study described the demographics, co-morbidities and outcome of critically ill COVID 19 patients in an ICU of a tertiary care hospital. It showed males were more likely to be infected than females, age group were 
mostly affected in this study, were $61-70$ years, DM was the most common co-morbidities and Mean length of ICU stay were $6.9 \pm 3.6$ days. The overall mortality in this study was $48.8 \%$. As, this is a new dimension of clinical study, we need more data in multi center approach and long term follow up to know the actual outcome of critically ill COVID 19 patients.

Authors' contribution: ASMAA, RS planned the study, analyzed the data, wrote the manuscript. KF, FA, DKS, MS, SN, IJ were involved in patients care and follow up. All authors read and approved the final manuscript.

\section{Conflict of interest: Nothing to declare.}

\section{REFERENCES}

1. World Health Organization. Director-General's remarks at the media briefing on 2019-nCoV on 11 February 2020. http:// www.who.int/dg/speeches/detail/who-director-general-sremarks-at-the-media-briefing-on-2019-ncov-on-11-february2020 (Accessed on February 12, 2020).

2. World Health Organization. WHO Director-General's opening remarks at the media briefing on COVID-19 - 11 March 2020.

Available from: https://www.who.int/dg/speeches/detail/whodirector-general-s-opening- remarks-at-the-media-briefingoncovid-19-11-march-2020, accessed on June 1, 2020.

3. 20-fold rise in COVID-19 cases in Bangladesh since April 1 Archived 28 July 2020 at the Way back Machine, Dhaka Tribune, 14 April 2020

4. Research (IEDCR), Institute of Epidemiology, Disease Control and করোনাইনফো corona.gov.bd (in Bengali). Archived from the original on 22 March 2020. Retrieved 3 May 2020.

5. Guan WJ, Ni ZY, Hu Y, Liang WH, Ou CQ, He JX, et al.Clinical characteristics of coronavirus disease 2019 in China. N Engl J Med 2020; 382: 1708-20.

6. COVID-19 National Emergency Response Center E, Case Management Team KCfDC, Prevention. Coronavirus disease19: The first 7,755 cases in the Republic of Korea. Osong Public Health Res Perspect2020; 11: 85-90.
7. Grasselli G, Pesenti A, Cecconi M. Critical care utilization for the COVID-19 outbreak in Lombardy, Italy: Early experience and forecast during an emergency response. JAMA 2020; 323: 1545-6.

8. Young BE, Ong SWX, Kalimuddin S, Low JG, Tan SY, Loh $\mathrm{J}$, et al. Epidemiologic features and clinical course of patients infected with SARS-CoV-2 in Singapore. JAMA 2020; 323:1488-94.

9. Guan W, Ni Z, Hu Y, Liang W, Ou C, He J, Liu L. Clinical Characteristics of 2019 Novel Coronavirus Infection in China. N Engl J Med 2020; 382: 1708-20.

10. Shah P, Owens J, Franklin J, Mehta A, Heymann W, Sewell $\mathrm{W}$, et al. Demographics, co morbidities and outcomes in hospitalized Covid-19 patients in rural southwest Georgia. ANNALS OF MEDICINE 2020; 52(7): 354-60.

11. Ahmed NU, Islam MA, Kabir MA, Rahman M H, Sadat SMA. Clinico-Pathological Findings of Bangladeshi Covid 19 Patients with their Clinical Outcome: Study of A Cohort of 201 Cases.Journal of Bangladesh College of Physicians and Surgeons July 2020; 38 (COVID-19 Supplement Issue): 37 42.

12. Wang D, Hu B, Hu C, Zhu F, Liu X, Zang J, et al. Clinical characteristics of 138 hospitalized patients with 2019 novel corona virus-infected pneumonia in Wuhan, China [published online ahead of print 2020]. JAMA. 2020 March 17; 323(11):1061-9.

13. Zhang JJ, Dong X, Cao YY, Yuan YD, Yang YB, Yan YQ, et al. Clinical characteristics of 140 patients infected with SARSCoV-2 in Wuhan, China [published online ahead of print 2020]. Allergy.2020 Feb 19. Available https://doi.org/10.1111/ all.14238

14. Xie J, Wu W, Li S, Hu Y, Hu M, Li J, et al Clinical characteristics and outcomes of critically ill patients with novel corona virus infectious disease (COVID 19) in China: a retrospective multicenter study. Intensive Care Med. August 2020;46: 1863-72.

15. Rodriguez-Morales AJ, Cardona-Ospina JA, GutiérrezOcampo E, Penna RV, Holguin-Rivera Y,EscaleraAntezana JP, et al. Clinical, laboratory and imaging features of COVID19: a systematic review and meta-analysis. Travel Med Infect Dis 2020; 34:101623. 